\title{
How Iranian Women with Human Papillomavirus Infections Describe Their Male Counterparts' Risky Sexual Behaviours?
}

\author{
Fereshteh Jahdi' ${ }^{1}$,Effat Merghati-Khoei² ${ }^{2}$ Abbas Ebadi ${ }^{3}$, Maryam Kashaniann ${ }^{4}$, Fatemeh Oskouie ${ }^{5}$ \\ ${ }^{1}$ Nursing Care Research Center, Iran University of Medical Sciences, Tehran, Iran. ${ }^{2}$ Iranian National \\ Center for Addiction Studies (INCAS), Institute for High-Risk Behaviors Reduction, Tehran University \\ of Medical Sciences, Tehran Iran. ${ }^{3}$ Behavioral Sciences Research Center, Life Style Institute, Faculty of \\ Nursing, Baqiyatallah University of Medical Sciences, Tehran, Iran. ${ }^{4}$ Department of Obstetrics and \\ Gynaecology, Iran University of Medical Sciences, Tehran, Iran. ${ }^{5}$ Nursing Care Research Center and \\ School of Nursing and Midwifery, Iran University of Medical Sciences, Tehran, Iran.
}

\section{ABSTRACT}

\section{BACKGROUND}

Human papillomavirus infection among sexually active women is a challenging clinical matter. Women's viewpoints toward healthy or risky sexual behaviours are regarded as central influences on male counterparts infected with sexually transmitted infection. In this study we aimed to explore the means by which women with HPV conceptualize their male counterpart's risky sexual behaviours.

\section{METHODS}

The qualitative research was carried out from September 2017 to December 2018 in the Firozgar hospital in Tehran, using content analysis. Participants were 30 HPVpositive women. Data was collected by three focus group discussions using a semistructured interviews guide. Moreover, we collected demographic and self-rated physical health data. Two co-authors served as coders.

\section{RESULTS}

Six themes including sexual life and gender dynamics, Resentment and risk, sexuality education and risk awareness, male oriented sexuality, substance abuse and sexual risk, marital construction and risk frame emerged from data. Data revealed that women had conceptualized their sexual self-concept in a maleoriented frame and put themselves at risk in order to confront this aggrieved partnership.

\section{CONCLUSIONS}

Our findings revealed views of affected women with papillomavirus infections. Having risky sexual behaviours from their spouse, multi partnerships, hiding the disease, lack of condom use, violence, lack of emotional support, financial support and inadequate sexual life role could affect the marital system in Iranian married women and leads them to adopt risky behaviour and subsequently to contract HPV.

\section{KEY WORDS}

Papillomavirus Infections, Sexually Transmitted Diseases, Risk-Taking, Sexuality, Female, Risky Behaviour

\author{
Corresponding Author: \\ Fatemeh Oskouie, \\ Nursing Care Research Center and \\ School of Nursing and Midwifery, \\ Iran University of Medical Sciences, \\ Tehran, Iran. \\ E-mail: oskouie.f@iums.ac.ir \\ fatemehoskouie@gmail.com
}

DOI: $10.14260 /$ jemds/2020/181

Financial or Other Competing Interests: Dr. Oskouie Reports Grants from Iran University of Medical Sciences, Outside the Submitted Work.

How to Cite This Article:

Jahdi F, Khoei EM, Ebadi A, et al. How Iranian women with human papillomavirus infections describe their male counterparts' risky sexual behaviours? J. Evolution Med. Dent. Sci. 2020;9(11):838-843, DOI:
Submission 26-12-2019,

Peer Review 19-02-2020

Acceptance 26-02-2020,

Published 16-03-2020. 


\section{BACKGROUND}

One of the most prevalent and epidemic sexually transmitted diseases (STDs) is human papillomavirus (HPV).(1,2) Over 150 forms of HPV have been reported, around 40 infecting the genital area $(3,4)$. Cervical cancer has resulted from sexually acquired certain HPV infections. (5) Women with HPV-positive are among society's most susceptible groups subjected to high-risk sexual behaviours. The total HR HPV infection prevalence was reported by Jamdar et al. to be $10.3 \%$ in Iran; this is very close to its prevalence across the world and could increase $^{(6)}$. An investigation on women in Tehran (Iran) aged 18 to 59 revealed that the HPV infection prevalence amongst those in polygamous marriages, divorced ones, as well as those reported husband's absence for over seven nights, was meaningfully higher(7). Risky sexual behaviours (RSBs) is influenced by many factors. (8) Studies revealed an association between sexually transmitted diseases and risky behaviours. $(9,10)$ Based on a systematic review, as well as the qualitative synthesis of opinions on HPV testing research conducted in the UK, women are probably inadequately informed and have a poor understanding with plenty of questions raised(11). Women, in particular, are vulnerable to STDs owing to social and biological concerns, as well as unequal power relationships between genders.(12) In Iran, there is not any research performed on the sexual behaviour dynamic of HPV infected women. In this paper, we report part of the findings of a larger study. We explored how a group of Iranian HPV positive women, give meaning to gender and sexuality in relation to RSBs compared to healthy encounters within the Iranian context of STDs. Therefore, this study aimed at exploring views of women with Papillomavirus Infections from the men risky sexual behaviours.

\section{METHODS}

As there was inadequate data on sexual relations and almost no preconceived hypothesis in this regard in the Iranian context, a conventional content analysis approach was applied in this qualitative research.(13) We recruited Iranian married HPV positive women $(n=30)$ aged 25-55 year old, lived with their permanent or casual spouse, were able to talk in Farsi and sexually active, with no history of psychological disorders, immune system insufficiency and diabetic disease, who have willingness to participate in the study. We approached the informants purposively. Focus group interviews conducted from September 2017 to December 2018 in the Firozgar hospital, the behavioural counseling center of a chosen educational hospital associated with the Iran University of Medical Sciences (IUMS), of Tehran, Iran. The center uses to provide some particular services, including psychological and medical care for people reporting risky sexual behaviours. Eligible subjects must have been diagnosed with HPV through laboratory data. The incentive in this study was 300,000 IR Rails gift card.

\section{Data Collection}

Data were collected through focus group discussion (FGD). The FGD is a suitable method in producing data from the person's values and exploring major social standards.(14)
FGDs lasted between $60-90$ min that was audio-taped. There were three women's focus groups. To mitigate privacy violations and optimize confidentiality, participants were asked to follow four basic rules: discuss their specific experiences communicated on RSBs and HPV, not to apply any names, speak one at a time, and keep confidentiality all said in the group. Subjects were ensured that their remarks could not be connected with their identities.

In order to make the participants more comfortable with each other, the discussion also helped to prepare the ground for the first focus group question (e.g., "how do you think of Healthy sexual behaviour?). Then (what is your opinion about RSBs and infections such as HPV?). (what is your reaction about your husband's RSBs)? The remained questions' order was not stable and left to the discretion of moderators to preserve the conversational flow. In each focus group, all questions were introduced and discussed. The remained questions concentrated on certain RSBs' facets.

The group sessions were facilitated by defining the contexts throughout RSBs was formed. A semi-structured interview guide initiated with an open-ended question 'how the RSBs are in married women in the context of STIs?' Afterward, the further questions were made upon the discussion according to the participants' responses; in mastering and experiencing RSBs and STIs, the subjects with various religiosity levels challenged the understandings of each other. In the FGDs, participants challenged, questioned, and answered each other. To gain mastery over the privacy and silence issues the followings were done: A) speaking style, look, posture, and gesture all were controlled, B) participants were consulted on their sexual life, if necessary, C) they were assured that their private risky sexual experience in the STIs context would be applied just to complete the study, and D) each woman was provided with a pseudonym to have privacy

One of the most commonly used purposive sampling approaches is maximal variation sampling.(15) In this method, subjects and study settings are chosen in a broad variety of variations in the subject matter under investigation. Participant selection with a variety of views and perspectives helps scholars to understand better and acquire richer data.(16) Informants were chosen from various age groups, education level, employment status, religion, as well as sexual experiences/marriage length, to obtain maximum variation in the data. Once three focus group discussions were held, data saturation was reached. No novel data, indeed, were obtained from the last FGD.(17)

\section{Data Analysis}

The data were analysed by the conventional content analysis using the Garnieham and Lund man method. Whole interviews or observational protocols are the most appropriate unit of analysis in this method.(17) While collecting the data, its analysis began. Prior to the next focus group interview or discussion, each focus group discussion was transcribed precisely and analysed. By reading and rereading, data comprehension was gained. The meaning units were extracted from the statements in the next phase. An overall notion was achieved after some readings; the FGDs' text was divided into numerous meaning units, then the meaning units were summarized, compressed, and extracted in the form of code applying line-by-line coding. Codes were 
made throughout repetitive debates between scholars; the codes then were clustered on the basis of differences and similarities in classes and sub-classes. Categories were extracted from the latent content of FGDs texts. The MAXQDA software, version 10 , was applied to manage the extracted codes.

\section{Trustworthiness}

Lincoln and Guba's suggested criteria of dependability, credibility, as well as transferability, which were considered in the study.(18) Five of the participants were asked to review and confirm the FGDS and the findings' summary in order to improve credibility (member check).The FGDs' transcripts first were coded by the first author (FJ). Two other coauthors who were expert in qualitative methods reviewed the transcripts and codes. All study members consulted and cooperated in all analysis phases. The data analysis process was checked with four persons acquainted with content analysis' qualitative approaches to assure reliability, consistency, and substantive codes (peer check). We described the context, sampling and analysis method in detail and included the quotations in the results to facilitate the judgment of transferability by the readers.

\section{Ethical Considerations}

The investigators completely introduced themselves, clarified the study objectives, and assured the subjects about their information confidentiality. All participants were asked for oral and written their informed consent to take part in the FGD and record their interviews via a digital recorder. The entire data collected was anonymous. All subjects were provided with pseudonyms; then, they were informed that participating in the research is voluntary, withdrawing at any time is allowed, and none of them will be named in any extracted publications from the research. Rejecting to partake in the research was not problematic for the service or care received at the center. The whole records and transcriptions saved in a protected and coded format. The Ethics Committee of Iran University of Medical Sciences approved the research; No. 1395.95-03-123-29572.

\section{RESULTS}

\section{General Findings}

The participants' average age was 41 years (age range: 25-59 years old). The mean length of their marriage were 7.8 years. The other participant characteristics are shown in (table 1).

\begin{tabular}{|ccc|}
\hline Variables & Category & Number (\%) \\
& $35 \leq$ & $12(40)$ \\
Age (Yrs.) & $35-44$ & $10(33.4)$ \\
& $45 \geq$ & $8(26.6)$ \\
Educational level & Bachelorof Science and more & $4(13.33)$ \\
& Diploma & $10(33.33)$ \\
Employment status & High school and less & $16(53.34)$ \\
& Housewife & $26(86.67)$ \\
Religion & Employed & $4(13.33)$ \\
& Shiae & $29(96.67)$ \\
Marriage length & Sonni & $1(3.33)$ \\
& $5 \leq$ & $10(33.3)$ \\
& $5-9$ & $14(46.7)$ \\
\hline \multicolumn{2}{c}{ Table 1. Demographic Characteristics of Participants } \\
\multicolumn{2}{c}{} \\
\multicolumn{2}{c}{}
\end{tabular}

With regard to the explanation views of women affected with papillomavirus infections from the men RSBs, 800 primary cods, ten sub-categories and six main categories emerged from the data (table 2).

\begin{tabular}{|cc|}
\hline Main Classes & Sub-Classes \\
Sexual life and gender dynamics & Unique femininity Gender roles \\
Resentment and risk & Men's violence Multi partnerships \\
Sexuality education and risk awareness & Hiding the disease Lack of knowledge \\
Male oriented sexuality & Lack of condom use \\
Substance abuse and sexual risk & Having risky sexual behaviour \\
Marital construction and risk frame & Sexual life role Emotional relationship \\
\hline $\begin{array}{c}\text { Table 2. Main Classes and Sub-Classes from Views of Affected Women } \\
\text { with Papillomavirus Infections towards Men's Risky Sexual Behaviours }\end{array}$ \\
\hline
\end{tabular}

\section{Sexual Life and Gender Dynamics}

This category included two sub-categories including unique femininity and Gender roles.

Unique Femininity

Women's narratives revealed the gender-specific lifelong sexual understanding. They believed women are sexual because men sexual needs are only fulfilled by women. This mindset led them to act as a sexual object to satisfy a man sexually. Participant 5 had her own strategy to show her spouse how powerful she is in their sexual interactions. Throughout 10 years of' marital life, she posed her husband that her femininity is unique, narrative reveals, she has been playing a role to control her man due to her specific mindset: "...you know...men are kind of simple...I know my husband, I would never let him go and learn about other women...he just thinks about me, I did this that he is tide up with me, nobody else...this is femininity kind of trick..." (P6, FGD1)

\section{Gender Roles}

Women from the second and third generation believed that sexuality is a natural phenomenon, but not gendered because it is a basic need of both genders required to be met. Contrary to some viewpoints of other participants, these women believed in sexual equality and narrated against male dominant sexuality. They highlighted the emotional relationship in favour of a woman at the time of sexual encounters: From women's viewpoints, the relationship between husband and wife is not just sexual. A 44-year-old woman stated that: "I do not believe in gender differences. I only say that if we are satisfied with our relationships, then we will not be able to do risky sexual behaviours" (P 14, FGD2).

\section{Resentment and Risk}

\section{Men's Violence}

Participants reported that they had experienced men's violence as a risk factor for women's desire to have another male partner. A 31 years old, reported that- "If your Husband fights with you or gets drunk, so you do not want to deal with him. And if you think about someone else, you will go to someone who has good behaviour and chooses him" (P7, FGD1).

\section{Multi Partnerships}

From the viewpoint of subjects, men's violence may make them anger overachieving a sense of sadness and attaining negative feeling in relationships and having Multi partnerships. A 34-year-old woman specified that: "I believe a man who betrays, screams, scolds, smokes, abuse his wife and does not matter his family for him, he doesn't deserve to live 
with his wife, and it's natural to be with someone else you love" (P21, FGD3).

\section{Sexuality Education and Risk Awareness}

Lack of Knowledge

Women who had genital warts mentioned that they did not know HPV is a STDs. A 23-year-old subject stated: "'it's in our minds; HPV is the same as HIV"(P10, FGD1)

Hiding the Disease

Participants did not know HPV is a STDs; they were upset that their husbands had the disease and did not say anything about it to them. A 36-year-old stated that: "When doctor said that: "You have been infected, I cried, my husband, said, "I do not have a relationship, but after I read the internet, I realized that I got it from him because I had seen some rash on his penis. I want to be separated from him. What did me guilty of? I do not have sex with him anymore. If they had taught us, we have known how to prevent it at least" (P24, FGD3).

\section{Male-oriented Sexuality}

Lack of Condom Use

Based on the subjects' claims, a majority of males do not apply a condom in anal sex with their permanent or casual partners. A40-year-old said; "The reason males in oralvaginal sex do not apply protection tools is their inadequate familiarity and information. Besides, AIDS and HPV is a disease that got in the human body by mucus, and mouth has mucus" (P28, FGD3).

Men's Attitudes towards Preventive Methods Use

Sexuality is a vital concern in human social life so that an approach to it influences the success or failure in the domain. Accordingly, men's attitude towards their wives is important. The argument is that males are seeking sexual pleasure in relationships, and they assume low the risk of being infected with HPV by their wives; thus, they do not apply condoms regularly. One of the participants added: "in sexual relationships, males behave in a different way as compared with females. Males, in their sexual intercourse with prostitutes and single non-virgin females, obligate to vaginal sex, employ condoms since they believe that the risk of being infected with AIDS in these partners is higher". (P30, FGD3)

\section{Substance Abuse and Sexual Risk}

A strong association of HPV with risky sexual behaviour engagement has been reported by women. A few subjects disagreed and reported abstention of liquor or less sexual experience. Such subjects, however, defined their behaviour as abnormal as well. There were particular mechanisms fundamental to how liquor results in sex variations; however, the results were consistent: married women, or went to locations, where liquor is, to find a sex partner. As A 30-yearold woman said: "My husband drinks liquor and has unconventional intentions from me, He makes me drink the liquor, so I also accompany with him because I do not want to feel pain during anal intercourse". (P1, FGD1)

\section{Marital Construction and Risk Frame}

Analysis of the women's experiences explored women's orientations toward marital commitment. The role sexual life plays in the formation of marital commitment was predominant in women's narratives.
The Role of Sexual Life

A 45-year-old woman declared that: "If you feel your husband loves you, you'll have sex with him; therefore, he will meet his sexual needs. So, I use my sex till he wants to have a mutual commitment". (P9, FGD1)

\section{Emotional Relationship}

An emotional and close relationship, sense of humour, commitment, affirmation of man, love and affection, the understanding of the critical situation by the man is all that matters to a woman who adheres to life. In this regard, A 36year-old female employee with one child stated that: "It is not right that one partner emotionally cares about his/her spouse and the other one not. For example, one says I do this as I like my husband ... to be satisfied. If so, one can upmost tolerate something against her desire for one-year s but not longer. Our personality has been formed and we cannot ignore our expectations". (P16, FGD2)

\section{DISCUSSION}

Based on the research findings, certain beliefs may have a vital part in triggering HPV, women positive to involve with RSBs. A great deal of provoking and permissive views on sexual relations have been provided by the present work. The data reveals that, gendered and partnership ideologies place women at risk of alteration of sexual behaviours from healthy to risky conducts. In relation to sexual activity, women's decision-making process was affected by various social dynamics. Some women believed in their feminine power to maintain their sexual life, while others said that having sexual satisfaction and emotional relationship in life can prevent men's high-risk behaviours and its consequences. In this regard, the findings of investigations revealed that Gender role is the normative behaviours and attitudes that are expected from biologically based individuals.(18) These roles have a broad concept, according to which responsibilities and duties are defined in the family, as the meaning of the gender role of defining masculinity and being a woman in society.(19) Gender attitudes reflect the attitude of individuals towards activities that are appropriate for men and women and includes the general concept of gender roles such as familyrelated duties.(20)

Research results offer crucial visions to women using drugs over non-injecting methods (inhaling, ingesting, snorting, chasing, smoking, or sniffing); however, a gap in authors' knowledge looks for potential alterations probably exist as compared with those inject drugs. Women, in the present work, were observed to be older, hardly probable to be active sexually, and highly probable to be separated or divorced than those of younger woman a study on women using drugs (WUD) in north-east India has indicated similar results.(21) Research results reveal that drug use moves women into a hectic lifestyle that affects their individual relationships negatively. This was in the vein of results from Lal et al., who claimed that women using drugs have more issues in their family and social relations, thus highly possible to divorce or separate than their male counterparts. (22) Participants in the study considered condom use in their sexual relationship could decrease partners' desire, which can be a risk factor for increase STDs. This was contrary to 
findings by Nesoff and colleagues who reported that: In main and casual partners both, reduced condom use was meaningfully related to earlier negative experiences with condoms; whereas, its use was not related constantly to the history of STIs diagnosis.(23) It was reported that satisfying the sexual needs of their partners is essential to preserve love and prevent them from dating others. They believe that the inclination of females to involve in sex will be seen by males as a sign of how they love them profoundly. Women, thus, fear to say 'no' to guarantee a firm partnership.(24) The participants in present study had compromised their ability to negotiate safe sex practices because their risk awareness was identified very low.

Finding revealed that women had conceptualized their sexual self-concept in a male-oriented frame and the majority of them put themselves at risk in order to confront this aggrieved partnership. They tried to get rid of offensive partnerships and make newer relationships to satisfy their emotional affairs, achieve social protection from a male partner, and bring stability in their lives to a certain degree. Furthermore, this narrative provides proof of how the female sexual partners obtain the power in order to inspire the men to involve in sex for firming the life base. A bright image of the power direct impact on the males is given by this account. In sum, women in monogamous marital life continue to imitate conventional forms of femininity that preserve gender inequality that is damaging to their sexual health. Double standard behaviours toward wedlock affair appeared to influence risky sexual encounters. Studies have demonstrated that, if people have, the findings of this research may be used in designing interventions, like improving preventive views or offering education on sexual relations in conservative societies. To the authors' knowledge, this is the first research that aims to offer an appropriate understanding of HPVpositive women. Couples' relationships are not exclusive to sex, but at first, there must be a good emotional relationship between husband and wife. If a woman realized that her husband does not like her, she tends to have another person to solve her emotional need.

\section{Strengths and Weaknesses}

We used qualitative research elements in an attempt to gain preliminary insights into the sexuality understandings of Iranian HPV positive women, the neglected research population. Limitation of generalizability is accepted in the qualitative researches' method. We attempted to conduct this research in a manner that was as tactful as possible, to put our respondents at ease and reduce attrition that could have stemmed from asking them a more detailed exploratory sexual question. This research has some strengths despite these limitations. It is the first such research in Iran studying perception HPV related to RSB in women. In addition, FGD was used, allowing to explore the feelings and perspectives of subjects on HPV related RSB. The FGD was fruitful since every subject had adequate time and a chance to share her feelings, views, as well as attitudes. The researcher had adequate time to probe and achieve in-depth reactions as subjects had a tendency to express themselves more liberally. The present work has significant implications practically and may assist in improving the services and interventions for HPV-positive women that decrease, in turn, the HPV related RSB in such people.

\section{CONCLUSIONS}

Our results revealed that from views of affected women with papillomavirus infections, having risky sexual behaviours from their spouse, multi partnerships, hiding the disease, lack of condom use, violence, lack of emotional support, lack of financial support and inadequate sexual life role could affect marital system and leads them to adopt risky behaviour and subsequently to contract HPV. For authorities, it is essential to take HPV as RBS and the program for health education into account in different local communities in Iran. People training to improve their understanding of HPV transmission and control is important.

\section{ACKNOWLEDGEMENT}

This article is an extract of a PhD thesis funded by Iran University of Medical Science.

\section{REFERENCES}

[1] CDC. The Link Between HPV and Cancer 2017. https://www.cdc.gov/hpv/parents/cancer.html.

[2] De Sanjosé S, Diaz M, Castellsagué X, et al. Worldwide prevalence and genotype distribution of cervical human papillomavirus DNA in women with normal cytology: a meta-analysis. The Lancet Infectious Diseases 2007;7(7):453-9.

[3] Bernard HU, Burk RD, Chen Z, et al. Classification of papillomaviruses (PVs) based on 189 PV types and proposal of taxonomic amendments. Virology 2010;401(1):70-9.

[4] Doorbar J, Quint W, Banks L, et al. The biology and lifecycle of human papillomaviruses. Vaccine 2012;30 (Suppl 5):F55-F70.

[5] WHO. Sexually transmitted infections (STIs). Fact sheet. Media centre. 2016 http://www.who.int/mediacentre/factsheets/fs110/en/.

[6] Jamdar F, Farzaneh F, Navidpour F, et al. Prevalence of human papillomavirus infection among Iranian women using COBAS HPV DNA testing. Infectious Agents and Cancer 2018;13(1):6.

[7] Khodakarami N, Clifford GM, Yavari P, et al. Human papillomavirus infection in women with and without cervical cancer in Tehran, Iran. International Journal of Cancer 2012;131(2):E156-61.

[8] Browne FA, Wechsberg WM, Bowling JM, et al. Correlates of male condom use skills among high-risk women in South Africa. Journal of Sex Research 2012;49(2-3):25563.

[9] Millay TA, Satyanarayana VA, O'Leary CC, et al. Risky business: Focus-group analysis of sexual behaviours, drug use and victimization among incarcerated women in St. Louis. Journal of Urban Health 2009;86(5):810-7.

[10] Jamshidimanesh M, Mousavi SA, Merghati-Khoei E, et al. Sexual risk behaviours constructed in Iranian women's life with substance use disorders: a new implication of 
human ecological theory. Addiction \& Health 2016;8(3):157-69.

[11] Hendry M, Pasterfield D, Lewis R, et al. Are women ready for the new cervical screening protocol in England? A systematic review and qualitative synthesis of views about human papillomavirus testing. British Journal of Cancer 2012;107(2):243-54.

[12] Falola T, Heaton MM. HIV/AIDS, illness and African wellbeing: University Rochester Press 2007.

[13] Hsieh HF, Shannon SE. Three approaches to qualitative content analysis. Qualitative Health Research 2005;15(9):1277-88.

[14] Sandelowski M. Focus on research methods-whatever happened to qualitative description? Research in Nursing and Health 2000;23(4):334-40.

[15] Speziale HS, Carpenter DR. Qualitative research in nursing: advancing the humanistic imperative: Philadelphia: Wolters Kluwer Health/Lippincott Williams \& Wilkins 2011.

[16] Polit DF, Beck CT. Nursing research: generating and assessing evidence for nursing practice. $8^{\text {th }}$ edn. Philadelphia: Lippincott Williams \& Wilkins 2008.

[17] Graneheim UH, Lundman B. Qualitative content analysis in nursing research: concepts, procedures and measures to achieve trustworthiness. Nurse Education Today 2004;24(2):105-12.
[18] Ben-David S, Schneider O. Rape perceptions, gender role attitudes and victim-perpetrator acquaintance. Sex Roles 2005;53(5-6):385-99.

[19] Kiani Q, Bahrami H, Taremian F. Study of the attitude toward gender role on submit gender egalitarianism among university students and employees in Zanjan (2008). ZUMS Journal 2009;17(66):71-8.

[20] Xu X, Lai SC. Gender ideologies, marital roles and marital quality in Taiwan. Journal of Family Issues 2004;25(3):318-55.

[21] Sharma V, Sarna A, Tun W, et al. Women and substance use: a qualitative study on sexual and reproductive health of women who use drugs in Delhi, India. BMJ Open 2017;7(11):e018530.

[22] Lal R, Deb KS, Kedia S. Substance use in women: Current status and future directions. Indian Journal of Psychiatry 2015;57(Suppl 2):S275-85.

[23] Nesoff ED, Dunkle K, Lang D. The impact of condom use negotiation self-efficacy and partnership patterns on consistent condom use among college-educated women. Health Education \& Behavior 2016;43(1):61-7.

[24] To SM, Tam Hl, Chu F. A qualitative study of the lived experiences of young Chinese females in condom use negotiations. International Journal of Adolescence and Youth 2013;18(4):248-62. 